\title{
Nutlin-3a, an MDM2 antagonist and p53 activator, helps to preserve the replicative potential of cancer cells treated with a genotoxic dose of resveratrol
}

\author{
Artur Zajkowicz • Małgorzata Krześniak • \\ Iwona Matuszczyk • Magdalena Głowala-Kosińska • \\ Dorota Butkiewicz • Marek Rusin
}

Received: 9 July 2012/Accepted: 29 April 2013/Published online: 11 May 2013

(c) The Author(s) 2013. This article is published with open access at Springerlink.com

\begin{abstract}
Resveratrol is a natural compound that has been intensely studied due to its role in cancer prevention and potential as an anti-cancer therapy. Its effects include induction of apoptosis and senescence-like growth inhibition. Here, we report that two cancer cell lines (U-2 OS and A549) differ significantly in their molecular responses to resveratrol. Specifically, in U-2 OS cells, the activation of the p53 pathway is attenuated when compared to the activation in A549 cells. This attenuation is accompanied by a point mutation (458: CGA $\rightarrow$ TGA) in the PPMID gene and overexpression of the encoded protein, which is a negative regulator of p53. Experimentally induced knockdown of $P P M 1 D$ in U-2 OS cells resulted in slightly increased activation of the p53 pathway, most clearly visible as stronger phosphorylation of $\mathrm{p} 53 \mathrm{Ser}^{37}$. When treated with nutlin-3a, a non-genotoxic activator of p53, U-2 OS and A549 cells both responded with substantial activation of the p53 pathway. Nutlin-3a improved the clonogenic survival of both cell lines treated with resveratrol. This improvement was associated with lower activation of DNA-damage signaling (phosphorylation of ATM, CHK2, and histone $\mathrm{H} 2 \mathrm{AX}$ ) and higher accumulation of cells in the G1 phase of the cell cycle. Thus, the hyperactivation of p53
\end{abstract}

A. Zajkowicz · M. Krześniak - I. Matuszczyk · D. Butkiewicz · M. Rusin $(\square)$

Center for Translational Research and Molecular Biology of Cancer, Maria Skłodowska-Curie Memorial Cancer Center and Institute of Oncology, Gliwice Branch, ul. Wybrzeże Armii Krajowej 15, 44-101 Gliwice, Poland

e-mail: rusinm@rocketmail.com

M. Głowala-Kosińska

Department of Bone Marrow Transplantation, Maria

Skłodowska-Curie Memorial Cancer Center and Institute of

Oncology, Gliwice Branch, 44-101 Gliwice, Poland by nutlin-3a helps to preserve the replicative potential of cells exposed to resveratrol.

Keywords p53 - Nutlin-3a - WIP1 - Resveratrol ·

Senescence

\section{Introduction}

In vivo studies have revealed that resveratrol delays cancer development and improves the health of mice on a highcalorie diet $[1,2]$. Resveratrol is also considered to be an anti-aging molecule, although different groups have published discordant results on this issue (reviewed in [3]). In vitro experiments with cancer cell lines indicate that resveratrol can induce cell-cycle inhibition, senescencelike growth inhibition, or apoptosis [4]. The mechanistic explanation of results from animal studies are unsatisfactory, partially because of the different concentrations of resveratrol present in the extracellular matrix of target cells of experimental animals and in cancer cell lines treated with resveratrol in vitro (reviewed in [5]).

At concentrations in the range $40-80 \mu \mathrm{M}$, resveratrol activates DNA-damage signaling, e.g., phosphorylation of histone H2AX on $\operatorname{Ser}^{139}$ [6-8], which can be phosphorylated by DNA damage-activated kinases [9]. A recently published study showed that resveratrol can be genotoxic even at concentrations as low as $5 \mu \mathrm{M}$, which can be achieved in laboratory animals by oral administration [10]. The mechanism underlying the genotoxic activity of resveratrol is not well understood. Resveratrol can inhibit DNA polymerases $\alpha$ and $\delta$ as well as DNA topoisomerase II $[8,11]$, so it has been hypothesized that resveratrol induces DNA damage by inhibiting enzymes that participate in DNA replication and/or repair (reviewed in [12]). 
This hypothesis predicts that cells in the DNA synthesis (S) phase would be the most sensitive to resveratrol.

Activation of DNA-damage signaling leads to activation of the p53 pathway, whose role is to stop the cell cycle and either facilitate DNA repair or permanently inhibit cell growth by inducing cellular senescence or apoptosis. For example, double-strand DNA breaks trigger activation of ATM kinase by autophosphorylation of Ser ${ }^{1981}$; activated ATM then phosphorylates $\mathrm{Thr}^{68}$ of CHK2 kinase. Activated CHK2 and ATM both phosphorylate $\mathrm{p} 53$ at the $\mathrm{N}$-terminus, thereby stabilizing p53 by preventing its association with MDM2, the ubiquitin ligase and negative regulator of p53 (reviewed in [13]). Activated p53 induces transcription of the gene encoding $\mathrm{p} 21$, which is the major effector of cell-cycle inhibition (reviewed in [14]). p53 transcriptionally induces its negative regulators, the MDM2 and WIP1 proteins ([15] and references therein). The latter protein can dephosphorylate and inactivate p53 as well as ATM and CHK2 [16-18]. The p53 pathway can also be activated non-genotoxically by nutlin-3a, an experimental drug designed to bind MDM2 specifically in its p53-binding pocket. Nutlin-3a prevents MDM2 from binding and destabilizing p53, leading to accumulation of high levels of p53 and upregulation of some p53-dependent genes, e.g., p21 and MDM2 [19].

In a previous study, we showed that resveratrol activates the p53 pathway in A549 and U-2 OS cells, as indicated by the accumulation of 553 protein and by the phosphorylation of p53 on $\operatorname{Ser}^{15}$ and $\operatorname{Ser}^{37}$. However, p21 was efficiently upregulated only in A549 cells, suggesting that the resveratrol-induced activation of the p53 pathway was attenuated in U-2 OS cells when compared with A549 cells. Despite their weak activation of the p53 pathway, U-2 OS cells exposed to resveratrol exhibited senescencelike growth inhibition. Moreover, we noticed strong differences between resveratrol-treated A549 and U-2 OS cells regarding expression pattern of the major cell-cycle regulators, e.g., BRCA1, cyclin B1, and RB [7]. The goal of this study was to explore further the molecular differences between A549 and U-2 OS cells, which could account for the different modes of p53 pathway activation. We conjectured that attenuation of p53 activation in U-2 OS cells might be specific to a subset of stress factors, such as those that trigger extensive post-translational modifications of p53, e.g., DNA damage. Hence, we planned to compare the status of nutlin-3a-induced p53 activation between A549 and U-2 OS cells. Moreover, we wanted to explore how nutlin-3a would modify the response of cells to genotoxic doses of resveratrol. The results of these experiments should help us understand the molecular mechanisms underlying the cytostatic activity of resveratrol, which is still a matter of debate.

\section{Materials and methods}

Cell culture, treatment, cytometric analysis of DNA content, and clonogenic assays

U-2 OS (human osteosarcoma, ATCC), A549 (human lung adenocarcinoma, ATCC), and GM07492 (normal human fibroblasts, Coriell Cell Repositories, Camden, NJ) cells were grown at $37{ }^{\circ} \mathrm{C}$ in an atmosphere containing $5 \% \mathrm{CO}_{2}$ in Dulbecco's modified Eagle's medium (DMEM, SigmaAldrich, St. Louis, MI) supplemented with $10 \%$ (U-2 OS, A549) or $15 \%$ (GM07492) fetal bovine serum (GibcoInvitrogen, Carlsbad, CA) and penicillin-streptomycin solution (Sigma-Aldrich). GM07492 cells were used between passages 11 and 12 .

The following stock solutions of chemicals were used: resveratrol (100 mM in DMSO; Sigma-Aldrich), nutlin-3a (10 mM in DMSO; Cayman Chemical, Ann Arbor, MI). Stock solutions were dissolved in culture medium to obtain the required concentration of the chemicals $(50 \mu \mathrm{M}$ resveratrol or $5 \mu \mathrm{M}$ nutlin-3a). Control cells were treated with medium containing indicated concentration of DMSO $(0.05$ or $0.1 \%)$.

Cell-cycle profiles were obtained by FACS analysis (FACSCanto flow cytometer, Becton-Dickinson, Franklin Lakes, NJ) following trypsinization of attached cells, ethanol fixation, RNase treatment, and propidium iodide (PI) staining.

For clonogenic assays, cells were seeded into 6-well plates. Starting the next day, the cells on experimental plates were treated for $96 \mathrm{~h}$ with $50 \mu \mathrm{M}$ resveratrol, $5 \mu \mathrm{M}$ nutlin-3a, or both substances; the control cells were mocktreated. After treatment, the cells were extensively washed and allowed to recover in fresh medium for $24 \mathrm{~h}$. Subsequently, the cells were trypsinized and counted, and 1,000 cells from each sample were seeded into $6 \mathrm{~cm}$ plates containing $5 \mathrm{ml}$ of fresh medium. After incubation for 9 (A549) or 12 (U-2 OS) days, colonies were fixed with 1:1 methanol:acetone and visualized with crystal violet. For each data point, large colonies were counted on two plates from at least three independent experiments.

Suppression of WIP1 expression by lentivirus-delivered shRNA

The expression of WIP1 protein in U-2 OS cells was suppressed using transduction-ready lentiviral particles purchased from Santa Cruz Biotechnology (Santa Cruz, CA). The manufacturer's protocol was followed. Control cells were transduced with lentiviral particles (from the same manufacturer) encoding scrambled shRNA particles that do not induce specific degradation of any known mRNA. Positively transduced cells were selected with 
puromycin. Due to high transduction efficiency, clonal selection was not required. The efficiency of knockdown was monitored by Western blotting. The day before treatment, the cells were trypsinized, seeded into new plates, and incubated in puromycin-free medium. Other resveratrol treatment conditions were as described above.

Immunofluorescence staining of histone $\mathrm{H} 2 \mathrm{AX}$ phosphorylated on serine $139(\gamma \mathrm{H} 2 \mathrm{AX})$

Staining was performed as described previously [7, 20]. Cells on Lab-Tek II slides (NUNC, Roskilde, Denmark) were fixed for 2 min at room temperature with $3.7 \%$ formalin in PBS (Sigma-Aldrich), washed, and then permeabilized in PBS containing $0.5 \%$ Triton X-100 (SigmaAldrich) for $10 \mathrm{~min}$. After washing, the cells were incubated in blocking solution (5\% BSA and $0.15 \%$ glycine in PBS) at room temperature for $30 \mathrm{~min}$. After $2 \mathrm{~h}$ incubation with anti-phospho-Ser139 histone H2AX antibody (JBW301, Upstate-Millipore, Billerica, MA; diluted 1:500 in blocking solution), the cells were extensively washed and incubated with Texas Red-conjugated anti-mouse IgG antibody (Vector Laboratories, Burlingame, CA), diluted 1:300. The stained cells were embedded in Vectashield with DAPI (Vector Laboratories) and were observed using a Nikon Eclipse E80i fluorescence microscope.

\section{Western blotting}

Control and treated cells growing on culture plates were harvested by trypsinization. For preparation of whole-cell lysates, PBS-washed cell pellets were frozen on dry ice and stored at $-70{ }^{\circ} \mathrm{C}$. Subsequently, the frozen cell pellets were suspended in IP buffer $(50 \mathrm{mM}$ Tris- $\mathrm{HCl}, \mathrm{pH} 8.0$; $120 \mathrm{mM} \mathrm{NaCl} ; 0.5 \% \mathrm{NP}-40$ ) supplemented with protease inhibitors (PMSF, pepstatin A, aprotinin, and leupeptin) and Phosphatase Inhibitor Cocktail 2 (Sigma-Aldrich). After incubation on ice for $20 \mathrm{~min}$, lysates were cleared by centrifugation $\left(14,000 \mathrm{rpm}, 4{ }^{\circ} \mathrm{C}, 20 \mathrm{~min}\right)$. Subsequently, two volumes of cleared lysate was mixed with one volume of solution containing $150 \mathrm{mM}$ Tris (pH 6.8), $6 \%$ SDS, $30 \%$ glycerol, $0.01 \%$ bromophenol blue, and $7.5 \% \beta$ mercaptoethanol. Lysates were then denatured $\left(95^{\circ} \mathrm{C}\right.$, $5 \mathrm{~min}$ ), chilled on ice, and stored at $-70{ }^{\circ} \mathrm{C}$.

Nuclear extracts were prepared by a method described previously [7]. After trypsinization and washing with PBS, cell pellets were treated with ice-cold EC buffer $(20 \mathrm{mM}$ Tris, $\mathrm{pH} 7.6 ; 10 \mathrm{mM} \mathrm{KCl} ; 2 \mathrm{mM} \mathrm{MgCl} 2 ; 1 \mathrm{mM}$ DTT; 0.5 mM EGTA; $0.5 \%$ NP40; $2.5 \%$ glycerol) supplemented with the protease and phosphatase inhibitors mentioned above. The suspension was incubated on ice for $10 \mathrm{~min}$. Subsequently, the samples were centrifuged at $310 \times g$ at $4{ }^{\circ} \mathrm{C}$ for $10 \mathrm{~min}$. The cytoplasmic fractions in the supernatants were discarded, and the pellets enriched in cell nuclei were frozen at $-70{ }^{\circ} \mathrm{C}$. After thawing on ice, pellets were lysed on ice for $20 \mathrm{~min}$ with RIPA buffer (0.5\% NP40, $0.5 \%$ sodium deoxycholate, $0.1 \%$ SDS in PBS) supplemented with protease and phosphatase inhibitors. After centrifugation and denaturation as described above, the nuclear extracts were stored at $-70{ }^{\circ} \mathrm{C}$.

Subsequently, $10-50 \mu \mathrm{g}$ aliquots of whole-cell lysates or nuclear extracts were separated by 6 or $11 \%$ SDSPAGE and electrotransferred onto PVDF membranes. The membranes were blocked for $1 \mathrm{~h}$ at room temperature in blocking solution (5\% skim milk solution in PBS with $0.1 \%$ Tween-20) and incubated with the indicated primary antibody. The following antibodies were from Cell Signaling Technology: anti-phospho-Ser1981 ATM (D6H9), anti-ATM (D2E2), anti-acetyl-Lys382 p53, anti-phosphoSer15 p53 (rabbit polyclonal antibody), anti-phosphoSer20 p53, anti-phospho-Ser37 p53, anti-phospho-Ser392 p53, anti-CHK2 (rabbit polyclonal antibody), anti-phospho-Thr68 CHK2, anti-phospho-Ser807/811 RB, and antiPLK1 (208G4). Anti-BRCA1 (D-9), anti-CDC2 (17), antip53 (DO-1), and anti-p21 ${ }^{\mathrm{WAF} 1}$ (F-5), anti-MDM2 (HDM2323) antibodies were from Santa Cruz Biotechnology. Anti-retinoblastoma protein (RB) antibody (clone mAB245) was from Chemicon International, and anti-143-3 $\sigma$ (Ab14116) and anti-PPM1D (WIP1) antibodies (Ab31270) were from Abcam (Cambridge, UK). HSC70 loading control was detected using the B-6 antibody (Santa Cruz Biotechnology). All incubations with primary antibodies were performed overnight at $4{ }^{\circ} \mathrm{C}$ in blocking solution. The secondary antibodies were HRP-conjugated and detected by chemiluminescence.

\section{Semi-quantitative real-time PCR}

Total RNA samples were prepared using the RNeasy mini kit according to the manufacturer's protocol (Qiagen, Hilden, Germany). cDNAs were synthesized using MuLV reverse transcriptase and random hexamers (Applied Biosystems, Foster City, CA). Measurements of p21, MDM2, PPM1D, and $\beta$-actin (internal reference) mRNA levels were performed using Real-Time $2 \times$ PCR Master Mix SYBR (A\&A Biotechnology, Gdynia, Poland) with oligonucleotide sequences GTG GAC CTG TCA CTG TCT TG and GAT TAG GGC TTC CTC TTG G for p21, GAG ACC CTG GTT AGA CCA AAG C and GCA CGC CAA ACA AAT CTC C for MDM2, CTC AAT GTG CCA GGA CCA AGA $G$ and TAT CTG CTC GGA GCA TAC GCT G for WIP1 (PPM1D), and GCA AGC AGG AGT ATG ACG AG and CAA ATA AAG CCA TGC CAA TC for $\beta$-actin mRNA [21]. PCR was performed using a CFX96 RealTime System (Bio-Rad, Hercules, CA). In each PCR run, 
the cDNA samples were amplified in triplicate. The relative quantification of the mRNAs for p21, WIP1, and MDM2 was performed using the $\Delta \Delta C_{T}$ method, with $\beta$ actin as the reference. Means and standard deviations were calculated from two independent treatments.

RT-PCR and sequencing of the WIP1 gene (PPMID) coding sequence

RNA and cDNA samples from untreated A549 and U-2 OS cells were prepared as described in the previous section. RT-PCR amplifications in the presence of $6.5 \%$ DMSO were performed using AmpliTaq Gold polymerase (Applied Biosystems); hence, the reactions were started with a 10 min incubation at $95{ }^{\circ} \mathrm{C}$ to activate the enzyme. Subsequently, 40 cycles of amplification $\left(94^{\circ} \mathrm{C}, 30 \mathrm{~s}\right.$; $58{ }^{\circ} \mathrm{C}, 15 \mathrm{~s} ; 72{ }^{\circ} \mathrm{C}, 75 \mathrm{~s}$ ) were performed. The $P P M 1 D$ cDNA sequence was amplified as two overlapping fragments encompassing the coding region. The primer sequences are given in the $5^{\prime} \rightarrow 3^{\prime}$ direction. The $5^{\prime}$ fragment $(1,012 \mathrm{bp})$ was amplified with the following primers: WIP-P1, GGC GTC GTC GAA GAT AAA CA; WIP-RT1, GTC AAG AGT GTG GAC ACT TG. The $3^{\prime}$ fragment (1,116 bp) was amplified with the following primers: WIPRT2, TTG TGG TGT CACCTG AAC CAG; WIP-P12, CAA GCA AGT ACA AGG CCA GGA. Subsequently, the PCR products were prepared for sequencing by exonuclease I and shrimp alkaline phosphatase digestion of unincorporated primers and deoxynucleotides. Prepared PCR products were sequenced using DigDye Terminator v3.1 Cycle Sequencing Kit (Applied Biosystems), and the sequences were acquired using a Genetic Analyzer 3500 (Applied Biosystems). The $5^{\prime}$ fragment was sequenced using the following primers: WIP-SQ1, AAC AAT AGT TGG CCG GCG AG; WIP-RT3, AGA AGG GTT TCA CCT CGT CC. The $3^{\prime}$ fragment was sequenced using the following primers: WIP-RT4, GAG GGT ATG ACT ACA CCT TG; WIP-SQ12, GTT CAA CAT CGG CAC CAA AT. Genomic DNA from A549 and U-2 OS cells was isolated by the chloroform extraction and ethanol precipitation method using the Genomic DNA Purification kit (Fermentas, Vilnius, Lithuania). Exon 6 of PPMID was amplified with the following primers: WIP-P11, CAA GCA AGT ACA AGG CCA GGA; WIP-P12 (see above). Exon 6 was amplified from genomic DNA as a template using AmpliTaq Gold polymerase in the presence of $5.2 \%$ DMSO. Thirty-five cycles of amplification $\left(94{ }^{\circ} \mathrm{C}, 30 \mathrm{~s}\right.$; $60{ }^{\circ} \mathrm{C}, 30 \mathrm{~s} ; 72{ }^{\circ} \mathrm{C}, 45 \mathrm{~s}$ ) were performed. The fragment was sequenced as described above with the following primers: WIP-SQ11, TCA CAT GCA TAG ATT TGT TGA GTT C; WIP-SQ12 (see above).

\section{Results}

U-2 OS cells exposed to resveratrol exhibit attenuated upregulation of mRNA and proteins encoded by p53 target genes

Despite accumulation of p53 protein induced by resveratrol, U-2 OS cells exhibited attenuated upregulation of p53 target genes (e.g., those encoding p21 and MDM2) when compared with A549 cells. This attenuation was visible at both the protein (Fig. 1a) and mRNA levels (Fig 1b). Potentially, insufficient post-translational modification of p53 could be the source of the apparently weaker p53 activity in U-2 OS cells. Previously, we found that in both cell lines, p53 was phosphorylated at $\mathrm{Ser}^{15}$ and $\mathrm{Ser}^{37}$, although the level of p53 with phosphorylated $\mathrm{Ser}^{37}$ was slightly higher in A549 cells [7]. This observation was confirmed in this study both in nuclear extracts (not shown) and in whole-cell lysates prepared in a separate experiment (Fig. 2). Moreover, in this study we observed that the other crucial modifications of p53 (phosphorylation of $\mathrm{Ser}^{20}$ and $\mathrm{Ser}^{392}$ as well as acetylation of Lys ${ }^{382}$ ) were similar in both cell lines (Fig. 2). Thus, the source of relatively weak p53 pathway activation in resveratrol-treated U-2 OS cells has not been determined, although it is associated with the lower phosphorylation level of $\mathrm{Ser}^{37}$. We hypothesize that the reduced ability of p53 to activate its target genes in U-2 OS cells could result from deficiencies in post-translational modifications of residues that were not studied by us, and/ or from altered activities of proteins functionally associated with $\mathrm{p} 53$.

The resveratrol-induced cell-cycle inhibition of A549 cells is associated with strong downregulation of proteins involved in regulation of the $\mathrm{G} 2 / \mathrm{M}$ checkpoint

The mechanistic basis of cell-cycle inhibition in U-2 OS cells exposed to resveratrol is not known [7]. The low activity of p21 in resveratrol-treated U-2 OS cells manifests as the persistent phosphorylation of RB protein (Fig. 3). Accumulated p21 inhibits RB phosphorylation (reviewed in [22]). Previously, we found that the different degrees of p53 pathway activation between A549 and U2OS cells were associated with differences in the expression levels of crucial cell-cycle regulators [7]. Strong upregulation of p21 in A549 was associated with repression of BRCA1, cyclin B1, and the phosphorylated form of RB. In this study, we expanded this analysis to other regulators of the G2/M checkpoint (Fig. 3). Using an antibody that specifically recognizes the phosphorylation of RB at $\mathrm{Ser}^{807}$ 
a

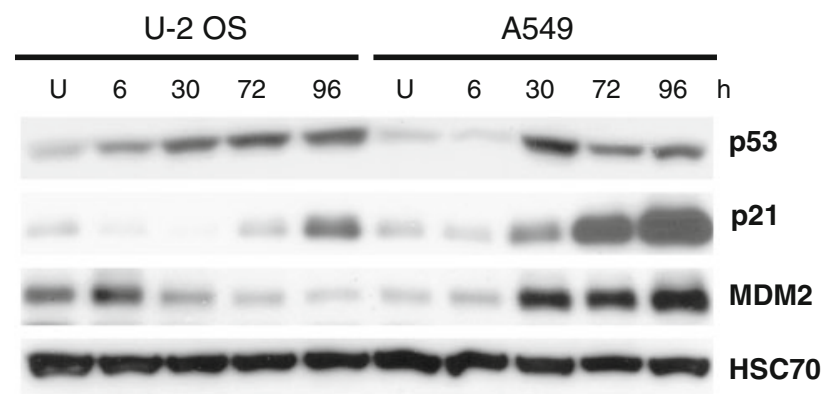

b
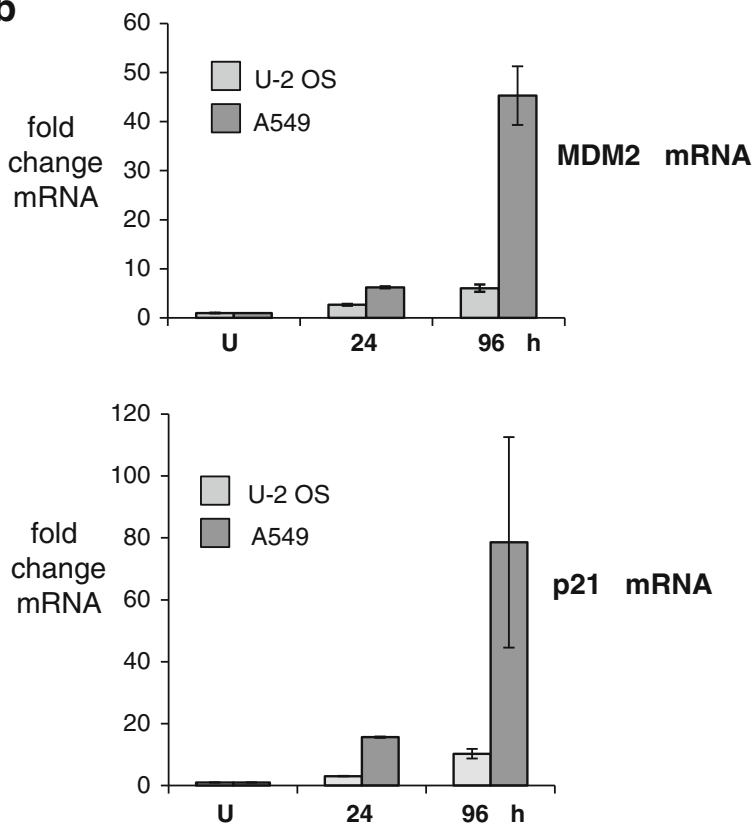

Fig. 1 a Expression of p53 and proteins encoded by p53-regulated genes (p21 and MDM2). Whole-cell lysates of untreated cells (U) and of cells treated for the indicated number of hours with $50 \mu \mathrm{M}$ resveratrol were analyzed. HSC70 is a loading control. b Changes in the levels of mRNAs encoding MDM2 or p21, measured by semiquantitative real-time PCR in RNA samples isolated from untreated (U) cells and from cells treated with resveratrol for 24 or $96 \mathrm{~h}$. The results represent the means and standard deviations from two independent experiments

and $\mathrm{Ser}^{811}$, we confirmed the inhibition of RB phosphorylation in A549 cells. Moreover, in these cells we detected strong repression of cyclin-dependent kinase CDC2 (CDK1), which, in complex with cyclin B1, is the major kinase that induces the G2/M transition. Interestingly, A549 cells also exhibited strong repression of another kinase, PLK1, which is crucial for entering mitosis (reviewed in [23]). Thus, unlike U-2 OS cells, resveratrol-treated A549 cells exhibited coordinated repression of major regulators of cell-cycle progression (cyclin B1, CDC2, BRCA1, phosphorylated RB, and PLK1). The cell-cycle inhibition of A549 cells treated with resveratrol can be explained in molecular terms: they cannot progress to mitosis due to a

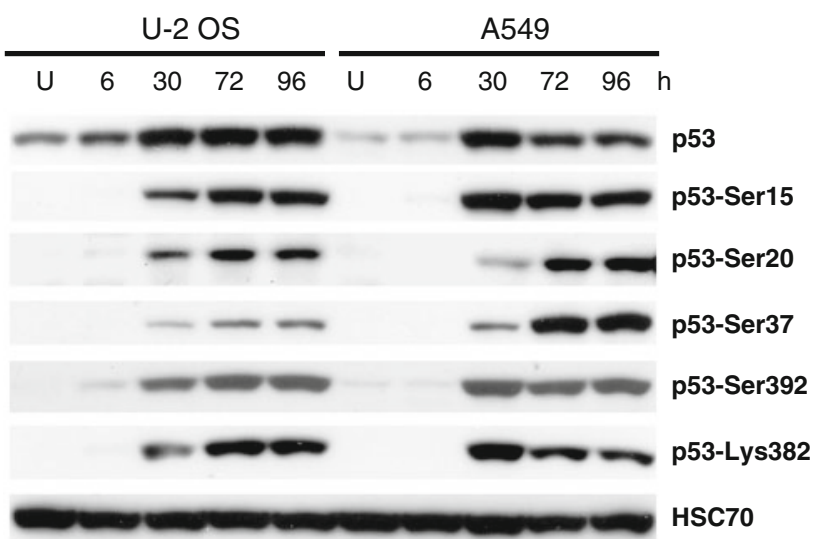

Fig. 2 Expression of p53 and its post-translationally modified forms in whole-cell lysates from untreated cells (U) or from cells treated with resveratrol for the indicated number of hours in a time-course experiment. Phosphorylation of serines 15, 20, 37, and 392 and acetylation of lysine 382 were examined

shortage of activated kinases (CDC2/cyclin B1, PLK1) that are crucial for starting cell division (reviewed in [23]). The mechanism underlying cell-cycle inhibition of U-2 OS cells exposed to resveratrol is unknown; furthermore, these cells also do not upregulate $14-3-3 \sigma$, the product of another p53 target gene involved in G2 arrest [24] (Fig. 3b).

Cell-cycle inhibition of resveratrol-treated U-2 OS cells is associated with persistent signaling through the ATM pathway

It is plausible that U-2 OS cells have an unidentified defect in p53 activation that leads to relatively weak upregulation of target genes during resveratrol exposure. Hypothetically, such a defect might involve a mechanism upstream of the p53 signaling pathway. In response to DNA damage, p53 is phosphorylated by the ATM and CHK2 kinases (reviewed in [25]). CHK2 is activated by ATM-mediated phosphorylation [26]. To examine the activation status of these p53 regulators, we monitored the phosphorylation of ATM Ser ${ }^{1981}$ and CHK2 $\mathrm{Thr}^{68}$. The ATM pathway was activated in both cell lines. In A549 cells, CHK2 phosphorylation peaked at the $30 \mathrm{~h}$ time point and diminished after 72 and $96 \mathrm{~h}$ (Fig. 3b). By contrast, in U-2 OS cells, CHK2 phosphorylation peaked after $96 \mathrm{~h}$. Thus, the signaling through the ATM-CHK2 pathway differed between the two cell lines: A549 cells exhibited activation and subsequent repression of the signaling, whereas in U-2 OS cells the signaling persisted for $96 \mathrm{~h}$. Similar patterns of H2AX phosphorylation have been reported previously [7].

U-2 OS cells overexpress $P P M 1 D$ gene, which encodes a negative regulator of the p53 pathway, WIP1

We hypothesized that repression of CHK2 phosphorylation in A549 cells at later time points of resveratrol treatment 


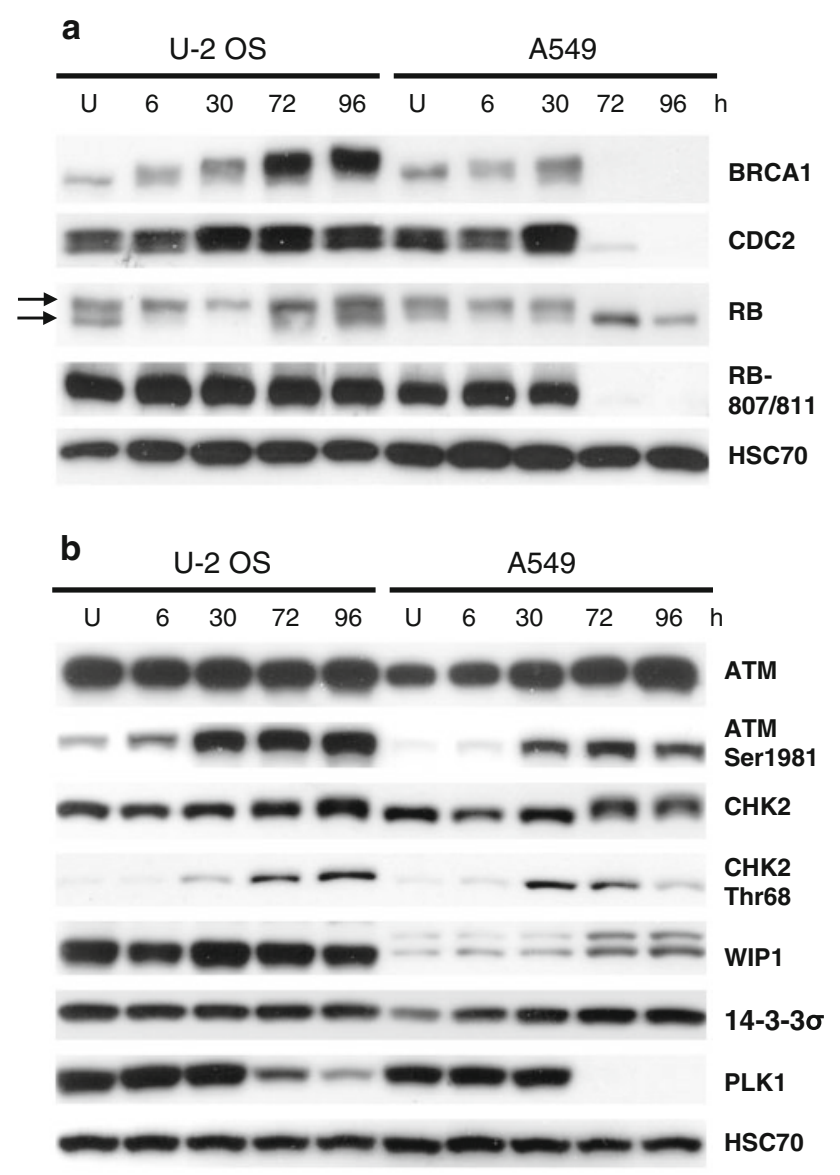

Fig. 3 a Expression of crucial cell-cycle regulators in nuclear extracts of untreated cells (U) or cells treated with resveratrol for the indicated number of hours. RB-807/811 shows the phosphorylation of $\mathrm{Ser}^{807}$ and $\mathrm{Ser}^{811}$ of RB. The upper and lower arrows show, respectively, the hyper- and hypophosphorylated forms of RB. b Expression and phosphorylation status of kinases activated by DNA damage (ATM and CHK2), expression of the phosphatase acting on them (WIP1), and expression of PLK1 kinase in whole-cell lysates of cells treated as in a. 14-3-3 $\sigma$ is an important regulator of $\mathrm{G} 2 / \mathrm{M}$ progression

was the result of strong activation of the p53 pathway. This conjecture is based on data reported by others, who found that WIP1 protein, the product of a p53-activated gene $(P P M 1 D)$, is able to dephosphorylate CHK2 [18]. Hence, we analyzed the dynamics of WIP1 expression in wholecell lysates of U-2 OS and A549 cells treated with resveratrol. As predicted, in A549 cells, WIP1 was upregulated at the 72 and $96 \mathrm{~h}$ time points. Surprisingly, however, in U-2 OS cells, WIP1 protein was overexpressed, and its expression did not exhibit major changes in response to resveratrol treatment (Fig. 3b).

Analysis of WIP1 expression in whole-cell lysates from untreated A549 and U-2 OS cells, as well as those from normal human fibroblasts (GM07492), revealed the lowest expression in fibroblasts, intermediate expression in A549, and the highest expression in U-2 OS cells (Fig. 4a).
Consistent with this, the expression of PPMID mRNA measured by semi-quantitative RT-PCR was about eight times higher in U-2 OS cells than in fibroblasts (Fig. 4b). Moreover, PPMID mRNA expression increased in both U-2 OS and A549 cell lines treated with resveratrol, but the magnitude of the increase was greater in A549 cells (Fig. 4c), further supporting the hypothesis that activation of p53 pathway is attenuated in U-2 OS. High expression of the PPM1D gene in U-2 OS cells is consistent with its role in carcinogenesis. PPMID is considered to be a protooncogene due to its role in negative regulation of p53 and its overexpression in breast, gastric, and pancreatic cancers, as well as in other tumors (reviewed [15]). To exclude the possibility that U-2 OS cells express a mutant form of the gene, we sequenced the PPMID cDNA amplified by RTPCR. Unexpectedly, we found a nucleotide substitution (Fig. 5). This $\mathrm{C} \rightarrow \mathrm{T}$ transition at position 1604 of the reference sequence NM_003620 generates a nonsense mutation in codon 458 (458:CGA $\rightarrow$ TGA, Arg $\rightarrow$ STOP). The location of $\mathrm{C} \rightarrow \mathrm{T}$ substitution at a $\mathrm{CpG}$ dinucleotide is consistent with deamination of 5-methylcytosine as the mutagenic mechanism [27]. This mutation was also visible in heterozygous configuration in the genomic DNA of U-2 OS cells (Fig. 5) indicating that the wild-type and mutant alleles of $P P M 1 D$ are present in equal copy numbers. We have not detected any other mutations in the coding regions of cDNAs from U-2 OS cells. Because these cells contained a major alteration in the gene encoding WIP1 protein, we hypothesized that the attenuated activation of the p53 pathway in U-2 OS cells is caused by overexpression of WIP1.

Knockdown of WIP1 protein in U-2 OS cells helps to activate $\mathrm{p} 53$

To determine whether the increased expression of WIP1 in $\mathrm{U}-2$ OS cells is the cause of the relatively weak activation of the p53 pathway, we performed a time-course experiment on cells in which WIP1 had been knocked down. The knockdown was performed using lentiviral particles containing three specific constructs encoding 19-25 nt shRNAs targeting the PPMID mRNA. Control cells were transduced with control lentivirus. The successful knockdown of WIP1 in U-2 OS did not result in the same molecular response to resveratrol observed in A549 cells, i.e., neither downregulation of $\mathrm{RB}$ phosphorylation nor repression of CDC2 was observed (Fig. 6). However, at early time points of resveratrol treatment or in untreated cells, WIP1 knockdown resulted in slightly increased expression of p21 and phosphorylated CHK2 (on $\mathrm{Thr}^{68}$ ). This effect was reproducibly observed in independent experiments. Moreover, knockdown of WIP1 resulted in 


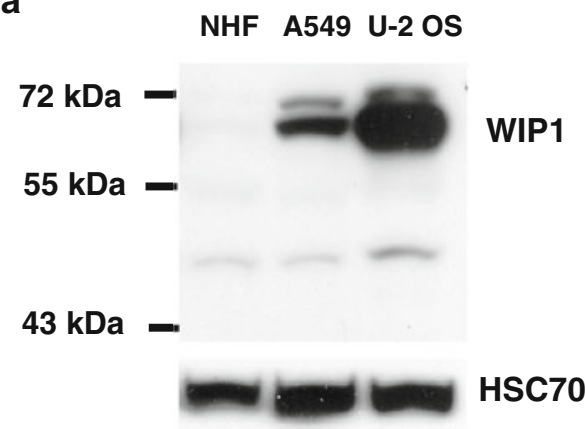

b

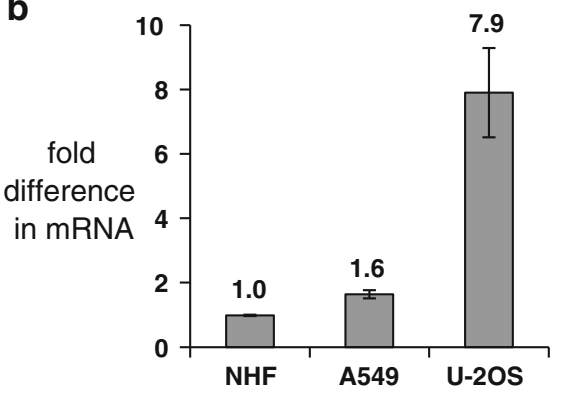

C

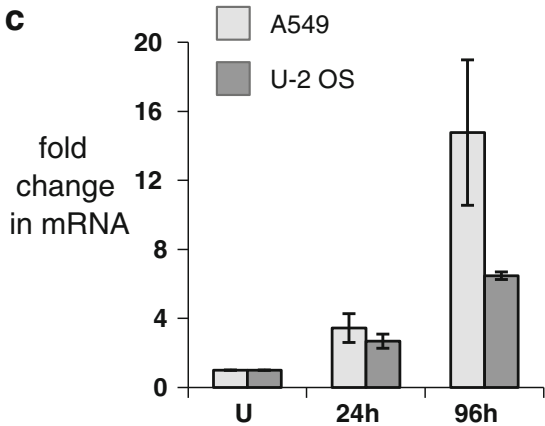

Fig. 4 a The expression of WIP1 protein in whole-cell lysates isolated from untreated normal human fibroblasts (NHF; GM07492) and A549 or U-2 OS cancer cell lines. The position of molecularweight markers is shown on the left. $\mathbf{b}$ Expression of mRNA encoding WIP1, measured by semi-quantitative real-time PCR in RNA samples from the cells shown in (a). The results represent the means and standard deviations from two independently isolated RNA samples. c Changes in the levels of mRNA encoding WIP1, measured by semiquantitative real-time PCR in RNA samples isolated from untreated cells (U) or from cells treated for 24 or $96 \mathrm{~h}$ with resveratrol. The level in the untreated population of either cell line was defined as 1. The results represent the means and standard deviations from two independent experiments

stronger resveratrol-induced phosphorylation of p53 on $\mathrm{Ser}^{37}$. To the best of our knowledge, this is the first study showing that WIP1 expression modulates the phosphorylation of p53 on this residue. We also observed an influence of WIP1 repression on 553 Ser $^{15}$ phosphorylation. Thus, downregulation of WIP1 in U-2 OS cells helps to activate p53, but does not result in major changes in expression of the cell-cycle regulators we examined (RB, CDC2).
Nutlin-3a upregulates the p53 pathway in both U-2 OS and A549 cell lines and induces the accumulation of G1 phase cells in resveratrol-treated populations

To examine the mechanism of p53 activation in U-2 OS cells more closely, we decided to determine whether the p53 pathway could be activated by a non-genotoxic agent, nutlin-3a, which apparently activates p53 in a way that does not require extensive phosphorylation of p53 on key serine residues [28]. In both cell lines, treatment with nutlin-3a resulted in upregulation of p53 and accumulation of the major p53 targets, p21 and MDM2 (Fig. 7a). As expected, p53 activation induced by nutlin-3a was not associated with strong phosphorylation of p53 at $\operatorname{Ser}^{15}$ and $\mathrm{Ser}^{37}$. For unknown reasons, U-2 OS exhibited increased acetylation of $\mathrm{Lys}^{382}$. Thus, in contrast to resveratrol, nutlin-3a has the ability to activate the p53 pathway in U-2 OS strongly. Because nutlin-3a and resveratrol activated the p53 pathway by different mechanisms, we next asked how nutlin-3a modulates the resveratrol-induced activation of p53 and DNA-damage signaling pathways. To the best of our knowledge, this has not been previously addressed in regard to resveratrol treatment, although earlier studies have described how nutlin-3a modulates the biological and molecular consequences of treating cells with various other genotoxic agents (see Discussion). In A549 cells, nutlin-3a attenuated p53 modifications induced by resveratrol (Fig. 7a). This effect was not visible in U-2 OS cells (two independent experiments showed this phenomenon). Based on these results, we hypothesized that in A549 cells, nutlin3a attenuates signaling through the ATM pathway, resulting in lower levels of p53 modifications at Ser ${ }^{15}$ and Ser ${ }^{37}$. To test this hypothesis, we looked for signs of ATM pathway activation (phosphorylation of ATM at Ser ${ }^{1981}$ and of $\mathrm{CHK} 2$ at $\mathrm{Thr}^{68}$ ) in cells treated as in Fig. 7a. The results were consistent with our hypothesis (Fig. 7b). Nutlin-3a diminished the ATM phosphorylation in A549 cells treated with resveratrol. In U-2 OS cells, the major sign of nutlin-induced ATM pathway downregulation was lower phosphorylation of CHK2. To support further the notion that the resveratrol-induced DNA-damage signaling in U-2 OS cells is reduced by nutlin-3a, we determined the percentage of cells containing high levels of $\gamma \mathrm{H} 2 \mathrm{AX}$. After $96 \mathrm{~h}$, the frequency of $\gamma \mathrm{H} 2 \mathrm{AX}$-overexpressing cells was significantly reduced in U-2 OS cells co-treated with both substances, relative to cells exposed only to resveratrol (Fig 7c, d). Moreover, we observed higher MDM2 expression in cells co-treated with resveratrol and nutlin-3a than in cells treated only with resveratrol (Fig. 7a). These findings are consistent with observations that high activity of DNA damage-activated kinases destabilizes MDM2 [29]. Based on these results, we conclude that nutlin-3a has the ability to reduce the activation of DNA-damage 

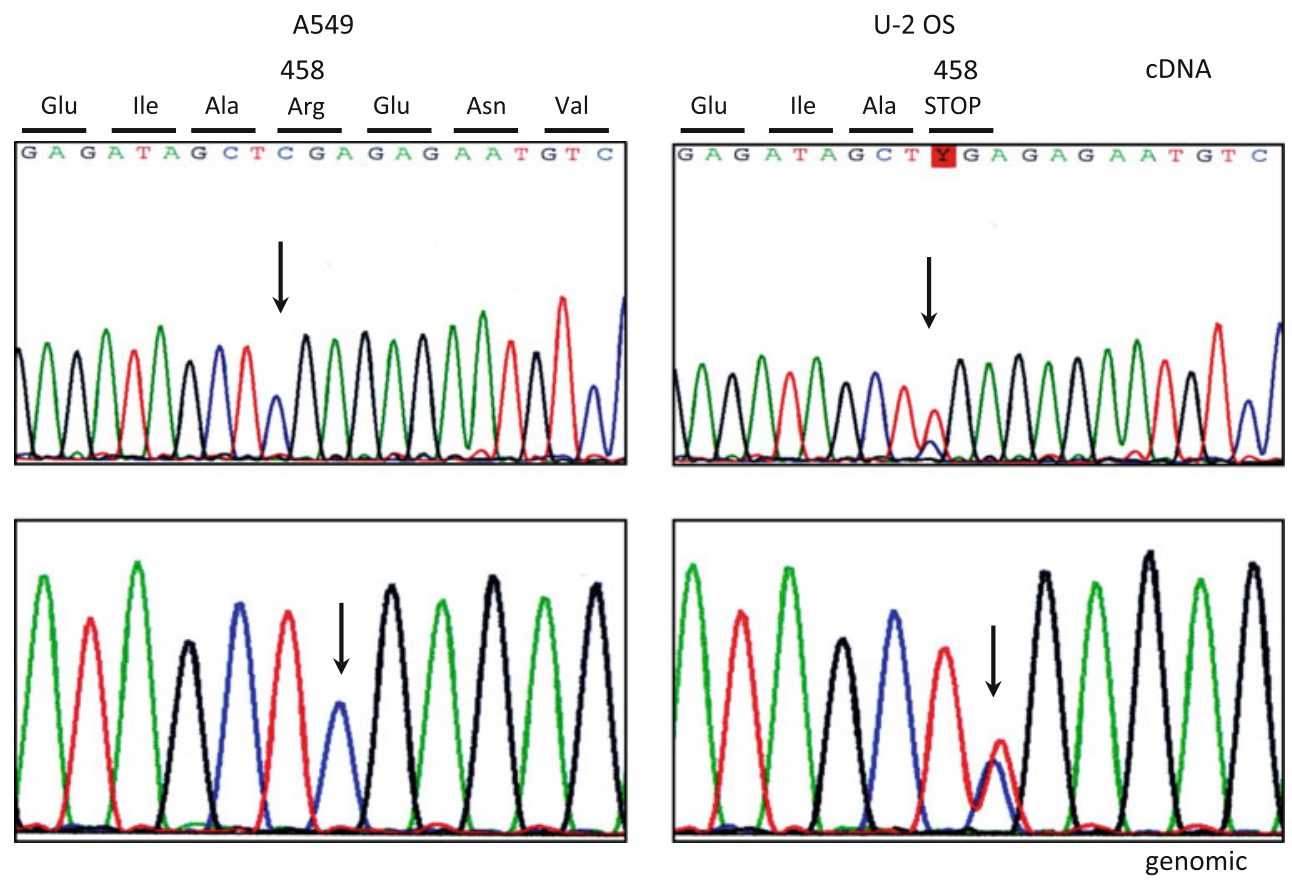

Fig. 5 Electropherogram showing a mutation in the gene encoding WIP1 (PPM1D) detected in the cDNA of U-2 OS cells (right, upper panel). The upper-left panel shows the relevant fragment of an electropherogram from wild-type cDNA sequence detected in A549 cells. The position of the mutant nucleotide is indicated by arrows. Note that in the electropherogram of U-2 OS cells, both wild-type and

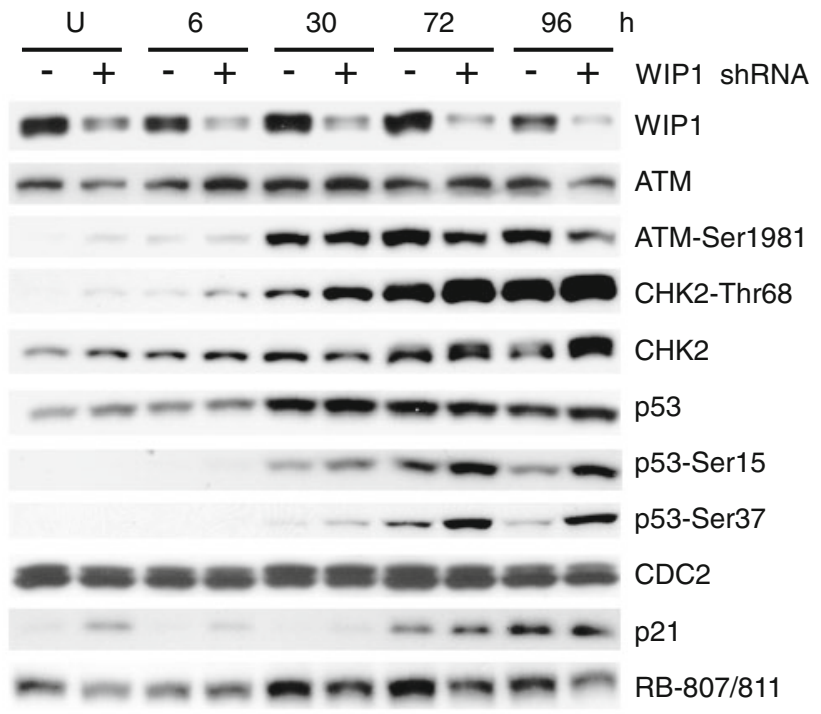

Fig. 6 Expression of DNA-damage signaling proteins (ATM, CHK2), their phosphorylated forms, p53, and post-translationally modified p53, as well as the major cell-cycle regulators (p21, CDC2, RB phosphorylated on Ser807/811), examined in whole-cell lysates from untreated U-2 OS cells (U) or from cells treated with resveratrol for the indicated number of hours in a time-course experiment. The pairs represent control cells $(-)$ and WIP1-knockdown cells (+); knockdowns were performed using lentivirus-delivered shRNA molecules. The efficiency of knockdown is shown by immunodetection of WIP1 protein mutant sequences are visible, indicating that both forms of mRNA are expressed. The mutation 1604: $\mathrm{C} \rightarrow \mathrm{T}$ (coordinates according to GenBank sequence, under Accession NM_003620) generates a stop codon in place of amino-acid residue 458. The lower panels present the relevant electropherograms of the genomic sequence, zoomed in on the mutant residue

signaling. To explain this, we hypothesized that nutlin somehow prevents the formation of DNA damage in cells exposed to resveratrol. Some observations indicate that resveratrol induces DNA damage mostly in cells that are replicating their DNA (reviewed in [12]). If nutlin-3a prevents the cells from entering the $S$ phase of the cell cycle, it might diminish the induction of DNA damage by resveratrol. The results of a cytometric analysis were consistent with this hypothesis (Fig. 8). As we previously reported [7], resveratrol-treated cells accumulated in S or late S/G2 phase of the cell cycle. Nutlin-3a alone blocked both cell lines either in G1 or in G2 (Fig. 8), consistent with data published by others [30]. S phase cells were virtually absent in populations treated with nutlin-3a for $96 \mathrm{~h}$. In co-treated cell populations, the frequency of cells in G1 phase significantly increased in both cell lines. Thus, diminished ATM pathway activation resulting from nutlin3a co-treatment is associated with inhibition of the cell cycle before the DNA replication phase.

Nutlin-3a treatment also helped us to identify the likely source of differences in the expression patterns of PLK1 and $\mathrm{CDC} 2$ between U-2 OS and A549 cells exposed to resveratrol for extended periods of time (Fig. 3). Based on data published by others showing that the genes encoding CDC2 and PLK1 are repressed by p53 [31, 32], we conjectured that repression of CDC2 and PLK1 in A549 cells, 
Fig. 7 a Expression of the indicated proteins in whole-cell lysates of cells treated for $96 \mathrm{~h}$ with $50 \mu \mathrm{M}$ resveratrol (R), $5 \mu \mathrm{M}$ nutlin-3a $(\mathrm{N})$, or cotreated with both substances (RN). b The expression of DNA-damage signaling proteins (ATM and CHK2) and their phosphorylated forms (ATMSer1981, CHK2-Thr68) in whole-cell lysates of cells treated as in

a. c Immunocytochemical staining of histone $\mathrm{H} 2 \mathrm{AX}$ phosphorylated on $\operatorname{Ser}^{139}$ $(\gamma \mathrm{H} 2 \mathrm{AX})$ in U-2 OS cells treated for $96 \mathrm{~h}$ with resveratrol or with resveratrol and nutlin (upper photographs). The locations of cell nuclei were visualized by DAPI staining. d The frequency of U-2 OS cells with upregulated $\gamma \mathrm{H} 2 \mathrm{AX}$; cells were treated as in a. Staining was performed after $96 \mathrm{~h}$ treatment. Means and standard deviations are shown. At least 400 cells in two independent experiments were examined a

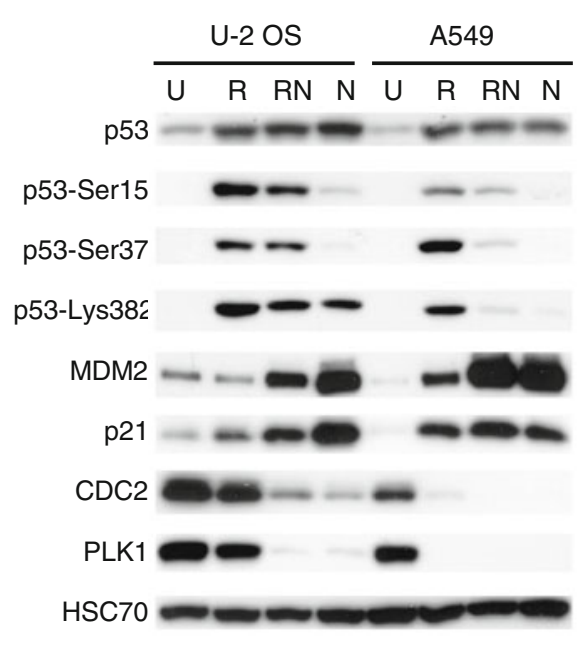

C

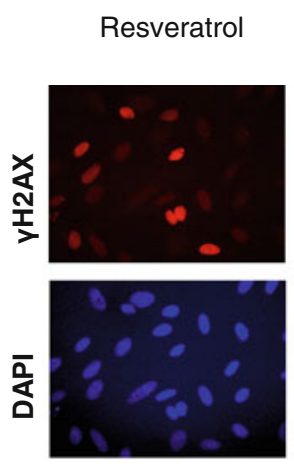

b

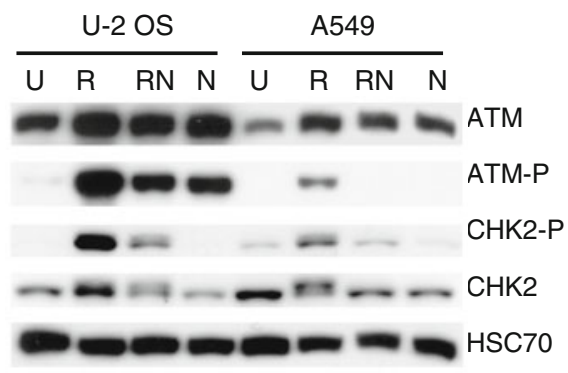

and their lack of repression in U-2 OS cells, were consequences of differences in the activation status of the p53 pathway. Indeed, this apparently was the case. Nutlin-3a alone strongly repressed PLK1 and CDC2 in A549 cells (Fig. 7a). Moreover, nutlin-3a was able to repress the two proteins in U-2 OS cells, even though these cells did not repress these proteins in response to resveratrol treatment. We conclude that when U-2 OS cells are treated with resveratrol, p53 can neither strongly upregulate p21 and MDM2 nor strongly repress PLK1 and CDC2; however, when p53 is activated by nutlin-3a, it efficiently activates and represses the p53-regulated genes.

Nutlin-3a helps to preserve the replication potential of resveratrol-treated cells

Next, we asked whether nutlin-3a could modify the fate of resveratrol-treated cells. Both nutlin-3a and resveratrol, acting alone or in combination, were able to inhibit the growth of both cell populations after 96-h treatments (Fig. 9a). Previously, we showed that resveratrol significantly decreased the clonogenic potential of both cell lines. This finding, together with the morphological and biochemical characteristics of the treated cells, indicated the induction of senescence-like growth inhibition [7]. In this study, we found that even though nutlin strongly inhibited growth of the cell population (Fig. 9a), it did not induce a very strong change in the clonogenic potential of cells (Fig. 9b, c). Consistent with previous results, we found that resveratrol significantly reduced the clonogenicity of both cell lines, although we noticed that U-2 OS cells were slightly more sensitive in this assay. Unexpectedly, however, nutlin-3a helped to preserve the replication potential of resveratrol-treated cells of both lines (Fig. 9b, c). Thus, even though both resveratrol and nutlin3 a could activate p53, only resveratrol strongly reduced clonogenic potential. Moreover, nutlin-3a had a dominant effect over resveratrol with respect to influence on clonogenic growth potential. Thus, increased activation of the p53 pathway induced by nutlin-3a did not reduce growth, but instead helped to preserve growth potential, in cells that were transiently treated with genotoxic dose of resveratrol. 

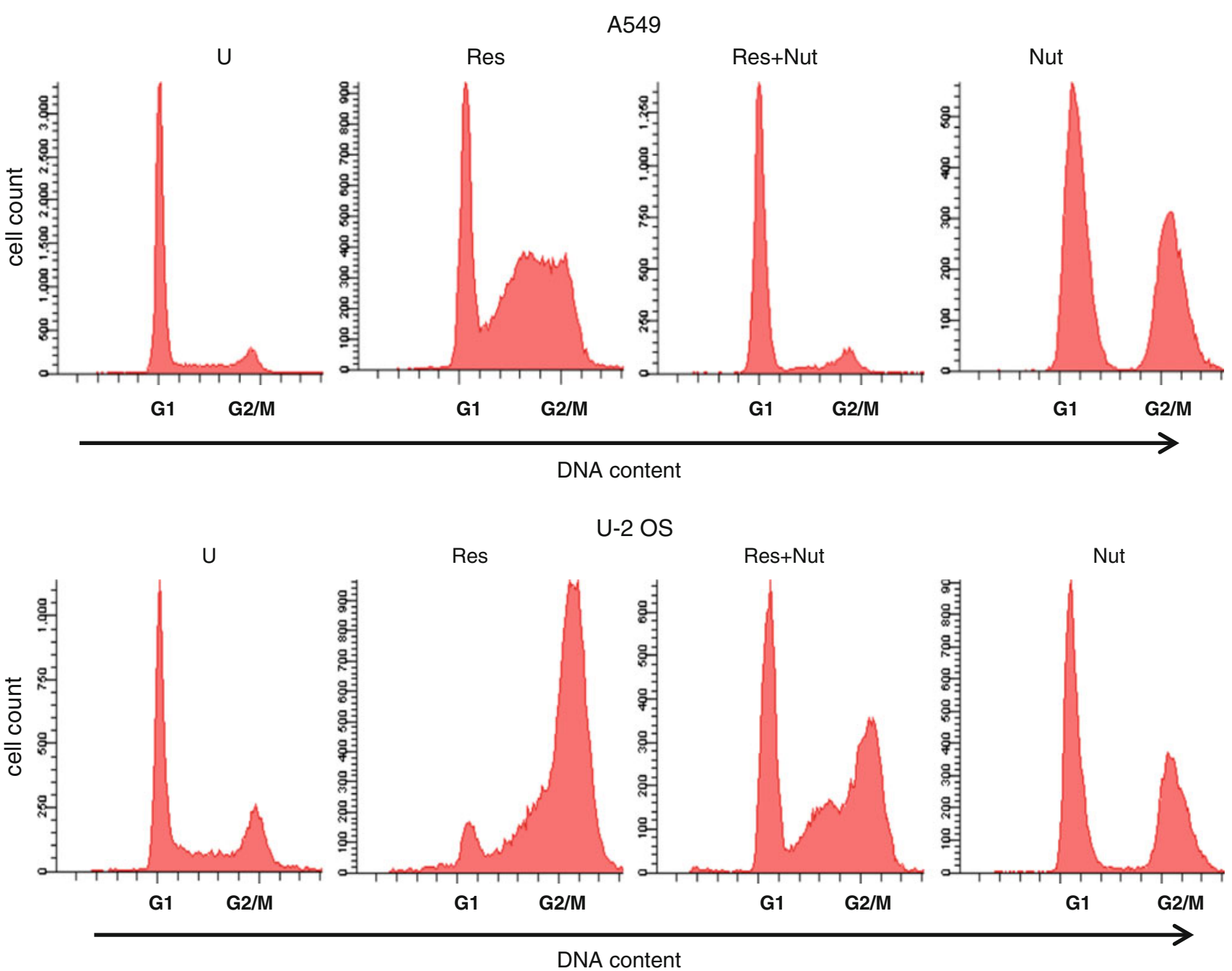

Fig. 8 The cell-cycle distribution of untreated cells (U) or cells exposed to resveratrol (Res), nutlin-3a (Nut), or the combination of both substances (Res+Nut) for $96 \mathrm{~h}$. The horizontal axis shows DNA

\section{Discussion}

The results of this study demonstrate that the p53 pathway, activated by the non-genotoxic agent nutlin-3a, can counteract the loss of replicative potential induced by a genotoxic dose of resveratrol. The protective mechanism of nutlin-3a may be complicated, but our observations are consistent with the hypothesis that nutlin-3a arrests the cell cycle at a phase when the cells are less sensitive to the genotoxic activity of resveratrol. Nutlin-3a markedly increases the frequency of resveratrol-treated cells arrested with G1-phase DNA content (Fig. 8). Moreover, nutlin-3a reduces the activation level of the DNA-damage signaling pathway (ATM, CHK2, and histone H2AX). We speculate that resveratrol induces replication stress, e.g., by inhibiting the activity of DNA polymerases [11]. This in turn elevates DNA-damage signaling, p53 activity, and stress- content. The values for G1- and G2/M-phases are marked. The vertical axis shows the cell count

induced senescence, leading to low clonogenic potential. When treated with nutlin-3a, cells preferentially arrest before or after the DNA replication phase, thereby decreasing the chance of DNA damage formation by resveratrol. Consequently, activation of DNA-damage signaling is low, and cells have normal replicative potential when nutlin-3a and resveratrol are removed from the culture medium.

Our hypothesis is consistent with the observations of Kranz and Dobbelstein [30], who revealed that nutlin-3a protects cells against the $\mathrm{S}$ phase-specific chemotherapeutic agent gemcitabine. The same authors found that nutlin3a pretreatment increased long-term survival and decreased apoptosis in U-2 OS cells irradiated with UV. A similar protective effect of nutlin-3a was observed in keratinocytes [33]. Moreover, Carvajal et al. [34] found that nutlin-3a pretreatment conferred protection of normal fibroblasts or 
Fig. 9 a Growth-inhibitory effect of resveratrol and nutlin$3 a$ in U-2 OS and A549 cells in a short-term assay. Equal numbers of cells were seeded onto culture dishes at the start of the experiment. The next day, control cells were mock-treated while experimental cells were treated with resveratrol, nutlin, or a combination of both substances. After $96 \mathrm{~h}$, the attached cells were washed, trypsinized, and counted. The graph was drawn from means and standard deviations from two independent experiments performed in triplicate. The number of cells on control dishes after $96 \mathrm{~h}$ culture is considered as $100 \%$. Note that a logarithmic scale is used. b The effects of resveratrol, nutlin, and the combination of both substances on the clonogenic potential of U-2 OS and A549 cells. The vertical axis shows the relative number of clones, which was defined as 1 for the untreated cells. The graphs show the means and standard deviations from three (U-2 OS) or four (A549) independent experiments. The $t$ test for two samples was used to determine statistical significance. c Example of plates from the clonogenic experiment. Colonies on $6 \mathrm{~cm}$ plates were stained with crystal violet a

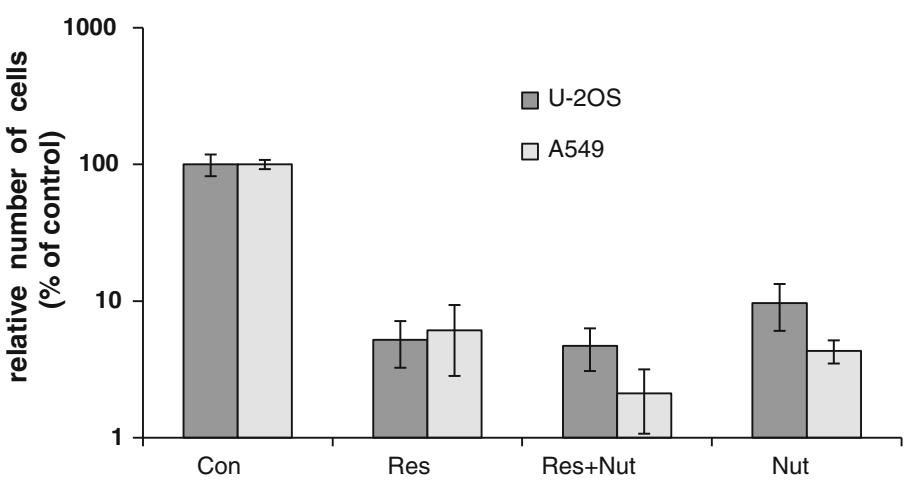

b

U-2 OS
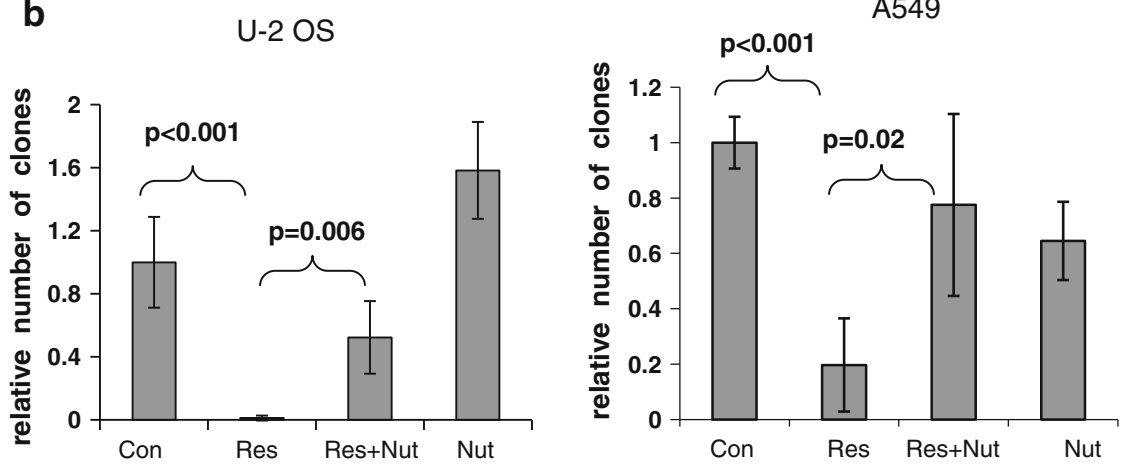

c

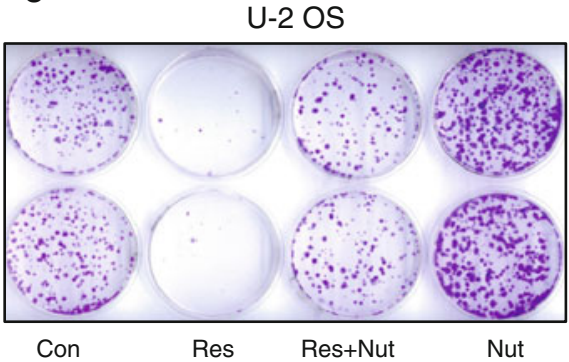

cancer cells with wild-type p53 against the cytotoxicity of paclitaxel. The results of our study and the aforementioned papers may be relevant to understanding the mechanisms underlying the radio- and chemo-resistance of some cancer cells. If p53 is activated by a non-genotoxic mechanism, it may help cancer cells to survive treatment with S phase- or $M$ phase-specific agents and restart cell divisions when the exposure ends. Thus, p53-negative tumors may be more sensitive to some drug combinations, as long as cancer cells are able to undergo p53-independent death.

Our findings and the results of others [30, 33, 34] apparently contrast with data showing that nutlin-3a sensitizes cancer cells to radiation $[35,36]$ or potentiates the cytotoxic activity of anti-cancer drugs in solid tumors [37]. These discrepancies may result in part from the different kinetics of nutlin-3a treatment, and/or measurements of different endpoints, in each study. For example, Cao et al. [35] showed by clonogenic assay that nutlin-3a sensitized a lung-cancer cell line to radiation. However, the nutlin-3a treatment was started just before irradiation and was continued $48 \mathrm{~h}$ afterward, so it is possible that nutlin-3a did not have time to prevent cells from entering the most sensitive phase of the cell cycle. A similar radiosensitizing effect of nutlin-3a in a clonogenic assay of laryngeal carcinoma cells was detected by Arya et al. [36]; again, however, the nutlin-3a treatment was performed short time (30 $\mathrm{min}$ ) before irradiation.

The protective role of nutlin-activated p53 shows some similarity to the results of in vivo experiments, in which p53 activity in mice was elevated either by the expression of an extra copy of the p53 gene [38] or through genetic downregulation of the MDM2 protein [39]. These genetically engineered mice exhibited decreased cancer incidence without signs of accelerated aging. Thus, p53 moderately overexpressed in a non-genotoxic way can extend lifespan. The suppression of cellular senescence by 
p53 under some experimental conditions has also been observed by others [40]. A protective role of p53 has also been suggested by the aforementioned authors, who found that nutlin-3a pretreatment protected against UV-induced toxicity [33]. Thus, accumulating evidence suggests that p53, at least under specific circumstances, acts as a survival factor.

We observed WIP1 overexpression in U-2 OS cells. This was not surprising, because WIP1 gene amplification/ overexpression has been detected in adenocarcinomas of the breast, ovary, and pancreas, in gastric carcinomas, and in other cancers, where it was usually associated with poor prognosis (review in [15]). WIP1 knockout mice are viable and cancer-resistant, but they display a range of abnormalities in male individuals including runting, reproductive organ atrophy, reduced fertility, and reduced longevity. Knockout mice of both sexes suffer from immunological abnormalities (reviewed in [15]).

In our study, knockdown of WIP1 increased phosphorylation of CHK2 on $\mathrm{Thr}^{68}$, consistent with the finding of Fujimoto et al. [41], who showed that WIP1 is able to dephosphorylate this residue. Moreover, we found that the knockdown resulted in higher phosphorylation of p53 on $\mathrm{Ser}^{37}$ and higher expression of p21. Elevated levels of p21 in cells from WIP1 knockout mice have also been observed by others [42]. Thus, overexpressed WIP1 in U-2 OS cells contributes to attenuated activation of the p53 pathway, at least in part by reducing (directly or indirectly) the phosphorylation of p53 molecules on $\operatorname{Ser}^{37}$. To the best of our knowledge, this is the first study showing that WIP1 contributes to decreased phosphorylation of this residue.

Unexpectedly, we detected a mutant version of $P P M 1 D$ gene in U-2 OS cells. To the best of our knowledge, this is the first reported point mutation of this gene. In vitro mutagenesis experiments performed by others showed that the WIP1 protein truncated at the C-terminus (composed of amino acids 1-375) is still able to inhibit phosphorylation of $\mathrm{Thr}^{68}$ of CHK2 protein [43]. Humans express an alternatively spliced $P P M I D$ mRNA in their lymphoid tissues and in testes; this alternative form encodes amino acids 1-420 plus an additional 10 amino acids that are not present in the major isoform of WIP1. The alternative WIP1 also has enzymatic activity [44]. These results suggest that if a C-terminally truncated mutant protein is expressed, it can still carry out some of the wild-type functions. However, we do not have evidence that the protein truncated by the mutation we found is present in cells at a detectable level; indeed, we have some reason to believe that it is not. Because the mutation shortens the reading frame by $25 \%$, the expected molecular weight of the mutant protein is $50 \mathrm{kDa}$. However, using the antiWIP1 antibody, we have not detected any protein of molecular weight lower than wild-type WIP1 $(66.7 \mathrm{kDa})$ or higher than $43 \mathrm{kDa}$ that was present specifically in U-2 OS cells (Fig. 4). The immunogen for this antibody was derived from within residues 200-300 of human WIP1, so it should be able to detect the truncated version of the protein. Hence, we speculate that the mutant gene encodes an unstable protein, whereas for reasons yet to be determined, the wild-type allele of the gene in U-2 OS cells produces an amount of WIP1 that is larger than that in A549 cells.

It is surprising to find a mutation that generates a stop codon in an overexpressed oncogene. Is it a coincidence that U-2 OS cells harbor a nonsense mutation in PPMID and also apparently overexpress the encoded protein from the wild-type allele, or are these two phenomena somehow related? Are PPMID point mutations common in human cancers? Further research is warranted to answer these important questions.

In conclusion, we report that resveratrol at $50 \mu \mathrm{M}$ concentration activates DNA-damage signaling and the p53 pathway, as well as reduces the replicative potential of cancer cell lines. The upregulation of p53 by the nutlin-3a in resveratrol-exposed cells reduces the activation of DNAdamage signaling, increases the frequency of cells in the G1 phase of the cell cycle, and prevents the loss of replicative potential. These findings indicate that the genotoxic and cytostatic activities of resveratrol depend on cell-cycle progression. The activation of the p53 pathway in resveratrol-exposed U-2 OS cells is attenuated relative to that observed in A549 cells. U-2 OS cells exhibit increased expression of the p53 antagonist PPM1D, but shRNAmediated knockdown of this protein only slightly increases the activation of p53. Unexpectedly, in U-2 OS cells, one allele of PPM1D gene contains a nonsense mutation. The molecular consequences of this mutation will be a subject of future investigations.

Acknowledgments This study was supported by the Polish Ministry of Science and Higher Education (Grant No. NN-401-597240, to MR) and by "Silesian BIO-FARMA" Project POIG.02.01.00-00-166/08. AZ was supported by the European Community from the European Social Fund within the DoktoRIS project. The MDM2 primers were designed by Katarzyna Szołtysek.

Open Access This article is distributed under the terms of the Creative Commons Attribution License which permits any use, distribution, and reproduction in any medium, provided the original author(s) and the source are credited.

\section{References}

1. Provinciali M, Re F, Donnini A, Orlando F, Bartozzi B, Di Stasio G, Smorlesi A (2005) Effect of resveratrol on the development of spontaneous mammary tumors in HER-2/neu transgenic mice. Int J Cancer 115:36-45 
2. Baur JA, Pearson KJ, Price NL, Jamieson HA, Lerin C, Kalra A, Prabhu VV, Allard JS, Lopez-Lluch G, Lewis K, Pistell PJ, Poosala S, Becker KG, Boss O, Gwinn D, Wang M et al (2006) Resveratrol improves health and survival of mice on a high-calorie diet. Nature 444:337-342

3. Agarwal B, Baur JA (2011) Resveratrol and life extension. Ann N Y Acad Sci 1215:138-143

4. Delmas D, Solary E, Latruffe N (2011) Resveratrol, a phytochemical inducer of multiple cell death pathways: apoptosis, autophagy and mitotic catastrophe. Curr Med Chem 18:1100-1121

5. Gescher AJ, Steward WP (2003) Relationship between mechanisms, bioavailibility, and preclinical chemopreventive efficacy of resveratrol: a conundrum. Cancer Epidemiol Biomarkers Prev 12:953-957

6. Tyagi A, Singh RP, Agarwal C, Siriwardana S, Sclafani RA, Agarwal R (2005) Resveratrol causes Cdc2-tyr15 phosphorylation via ATM/ATR-Chk1/2-Cdc25C pathway as a central mechanism for $\mathrm{S}$ phase arrest in human ovarian carcinoma Ovcar-3 cells. Carcinogenesis 26:1978-1987

7. Rusin M, Zajkowicz A, Butkiewicz D (2009) Resveratrol induces senescence-like growth inhibition of U-2 OS cells associated with the instability of telomeric DNA and upregulation of BRCA1. Mech Ageing Dev 130:528-537

8. Leone S, Cornetta T, Basso E, Cozzi R (2010) Resveratrol induces DNA double-strand breaks through human topoisomerase II interaction. Cancer Lett 295:167-172

9. Burma S, Chen BP, Murphy M, Kurimasa A, Chen DJ (2001) ATM phosphorylates histone $\mathrm{H} 2 \mathrm{AX}$ in response to DNA doublestrand breaks. J Biol Chem 276:42462-42467

10. Fox JT, Sakamuru S, Huang R, Teneva N, Simmons SO, Xia M, Tice RR, Austin CP, Myung K (2012) High-throughput genotoxicity assay identifies antioxidants as inducers of DNA damage response and cell death. Proc Natl Acad Sci USA 109:5423-5428

11. Stivala LA, Savio M, Carafoli F, Perucca P, Bianchi L, Maga G, Forti L, Pagnoni UM, Albini A, Prosperi E, Vannini V (2001) Specific structural determinants are responsible for the antioxidant activity and the cell cycle effects of resveratrol. J Biol Chem 276:22586-22594

12. Gatz SA, Wiesmüller L (2008) Take a break-resveratrol in action on DNA. Carcinogenesis 29:321-332

13. Batchelor E, Mock CS, Bhan I, Loewer A, Lahav G (2008) Recurrent initiation: a mechanism for triggering p53 pulses in response to DNA damage. Mol Cell 30:277-289

14. Kruse JP, Gu W (2009) Modes of p53 regulation. Cell 137:609-622

15. Lu X, Nguyen TA, Moon SH, Darlington Y, Sommer M, Donehower LA (2008) The type 2C phosphatase Wip1: an oncogenic regulator of tumor suppressor and DNA damage response pathways. Cancer Metastasis Rev 27:123-135

16. Lu X, Nannenga B, Donehower LA (2005) PPM1D dephosphorylates Chk1 and p53 and abrogates cell cycle checkpoints. Genes Dev 19:1162-1174

17. Shreeram S, Demidov ON, Hee WK, Yamaguchi H, Onishi N, Kek C, Timofeev ON, Dudgeon C, Fornace AJ, Anderson CW, Minami Y, Appella E, Bulavin DV (2006) Wip1 phosphatase modulates ATM-dependent signaling pathways. Mol Cell 23:757-764

18. Oliva-Trastoy M, Berthonaud V, Chevalier A, Ducrot C, Marsolier-Kergoat MC, Mann C, Leteurtre F (2007) The Wip1 phosphatase (PPM1D) antagonizes activation of the Chk2 tumour suppressor kinase. Oncogene 26:1449-1458

19. Vassilev LT, Vu BT, Graves B, Carvajal D, Podlaski F, Filipovic Z, Kong N, Kammlott U, Lukacs C, Klein C, Fotouhi N, Liu EA (2004) In vivo activation of the p53 pathway by small-molecule antagonists of MDM2. Science 303:844-848
20. Zajkowicz A, Rusin M (2011) The activation of the p53 pathway by the AMP mimetic AICAR is reduced by inhibitors of the ATM or mTOR kinases. Mech Ageing Dev 132:543-551

21. Mizuno S, Bogaard HJ, Voelkel NF, Umeda Y, Kadowaki M, Ameshima S, Miyamori I, Ishizaki T (2009) Hypoxia regulates human lung fibroblast proliferation via p53-dependent and independent pathways. Respir Res 10:17

22. Abbas T, Dutta A (2009) p21 in cancer: intricate networks and multiple activities. Nat Rev Cancer 9:400-414

23. Lindqvist A, Rodríguez-Bravo V, Medema RH (2009) The decision to enter mitosis: feedback and redundancy in the mitotic entry network. J Cell Biol 185:193-202

24. Hermeking $\mathrm{H}$, Lengauer $\mathrm{C}$, Polyak $\mathrm{K}$, He TC, Zhang L, Thiagalingam S, Kinzler KW, Vogelstein B (1997) 14-3-3 sigma is a p53-regulated inhibitor of $\mathrm{G} 2 / \mathrm{M}$ progression. Mol Cell $1: 3-11$

25. Boehme KA, Blattner C (2009) Regulation of p53-insights into a complex process. Crit Rev Biochem Mol Biol 44:367-392

26. Matsuoka S, Rotman G, Ogawa A, Shiloh Y, Tamai K, Elledge SJ (2000) Ataxia telangiectasia-mutated phosphorylates Chk2 in vivo and in vitro. Proc Natl Acad Sci USA 97:10389-10394

27. Cooper DN, Mort M, Stenson PD, Ball EV, Chuzhanova NA (2010) Methylation-mediated deamination of 5-methylcytosine appears to give rise to mutations causing human inherited disease in $\mathrm{CpNpG}$ trinucleotides, as well as in $\mathrm{CpG}$ dinucleotides. Hum Genomics 4:406-410

28. Thompson T, Tovar C, Yang H, Carvajal D, Vu BT, Xu Q, Wahl GM, Heimbrook DC, Vassilev LT (2004) Phosphorylation of p53 on key serines is dispensable for transcriptional activation and apoptosis. J Biol Chem 279:53015-53022

29. Stommel JM, Wahl GM (2004) Accelerated MDM2 auto-degradation induced by DNA-damage kinases is required for $\mathrm{p} 53$ activation. EMBO J 23:1547-1556

30. Kranz D, Dobbelstein M (2006) Nongenotoxic p53 activation protects cells against S-phase-specific chemotherapy. Cancer Res 66:10274-10280

31. Yun J, Chae HD, Choy HE, Chung J, Yoo HS, Han MH, Shin DY (1999) p53 negatively regulates cdc2 transcription via the CCAAT-binding NF-Y transcription factor. J Biol Chem 274:29677-29682

32. McKenzie L, King S, Marcar L, Nicol S, Dias SS, Schumm K, Robertson P, Bourdon JC, Perkins N, Fuller-Pace F, Meek DW (2010) p53-dependent repression of polo-like kinase-1 (PLK1). Cell Cycle 9:4200-4212

33. Kranz D, Dohmesen C, Dobbelstein M (2008) BRCA1 and Tip60 determine the cellular response to ultraviolet irradiation through distinct pathways. J Cell Biol 182:197-213

34. Carvajal D, Tovar C, Yang H, Vu BT, Heimbrook DC, Vassilev LT (2005) Activation of p53 by MDM2 antagonists can protect proliferating cells from mitotic inhibitors. Cancer Res 65:1918-1924

35. Cao C, Shinohara ET, Subhawong TK, Geng L, Woon Kim K, Albert JM, Hallahan DE, Lu B (2006) Radiosensitization of lung cancer by nutlin, an inhibitor of murine double minute 2 . Mol Cancer Ther 5:411-417

36. Arya AK, El-Fert A, Devling T, Eccles RM, Aslam MA, Rubbi CP, Vlatković N, Fenwick J, Lloyd BH, Sibson DR, Jones TM, Boyd MT (2010) Nutlin-3, the small-molecule inhibitor of MDM2, promotes senescence and radiosensitises laryngeal carcinoma cells harbouring wild-type p53. Br J Cancer 103:186-195

37. Roh JL, Kang SK, Minn I, Califano JA, Sidransky D, Koch WM (2011) p53 Reactivating small molecules induce apoptosis and enhance chemotherapeutic cytotoxicity in head and neck squamous cell carcinoma. Oral Oncol 47:8-15

38. García-Cao I, García-Cao M, Martín-Caballero J, Criado LM, Klatt P, Flores JM, Weill JC, Blasco MA, Serrano M (2002) 
"Super p53" mice exhibit enhanced DNA damage response, are tumor resistant and age normally. EMBO J 21:6225-6235

39. Mendrysa SM, O'Leary KA, McElwee MK, Michalowski J, Eisenman RN, Powell DA, Perry ME (2006) Tumor suppression and normal aging in mice with constitutively high p53 activity. Genes Dev 20:16-21

40. Demidenko ZN, Korotchkina LG, Gudkov AV, Blagosklonny MV (2010) Paradoxical suppression of cellular senescence by p53. Proc Natl Acad Sci USA 107:9660-9664

41. Fujimoto H, Onishi N, Kato N, Takekawa M, Xu XZ, Kosugi A, Kondo T, Imamura M, Oishi I, Yoda A, Minami Y (2006) Regulation of the antioncogenic Chk2 kinase by the oncogenic Wip1 phosphatase. Cell Death Differ 13:1170-1180

42. Bulavin DV, Phillips C, Nannenga B, Timofeev O, Donehower LA, Anderson CW, Appella E, Fornace AJ Jr (2004) Inactivation of the Wip1 phosphatase inhibits mammary tumorigenesis through p38 MAPK-mediated activation of the p16(Ink4a)p19(Arf) pathway. Nat Genet 36:343-350

43. Yoda A, Xu XZ, Onishi N, Toyoshima K, Fujimoto H, Kato N, Oishi I, Kondo T, Minami Y (2006) Intrinsic kinase activity and SQ/TQ domain of Chk2 kinase as well as $\mathrm{N}$-terminal domain of Wip1 phosphatase are required for regulation of Chk2 by Wip1. J Biol Chem 281:24847-24862

44. Chuman Y, Kurihashi W, Mizukami Y, Nashimoto T, Yagi H, Sakaguchi K (2009) PPM1D430, a novel alternative splicing variant of the human PPM1D, can dephosphorylate p53 and exhibits specific tissue expression. J Biochem 145:1-12 